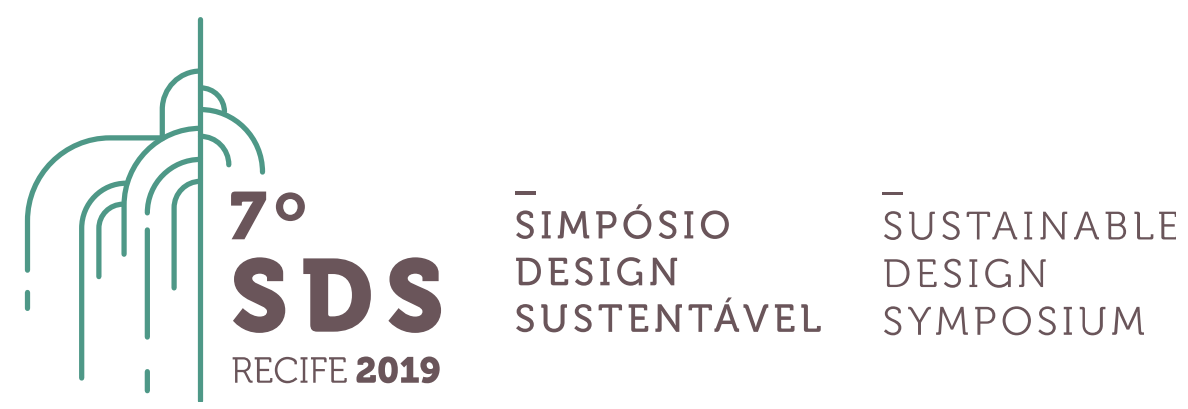

\title{
Crafting a Regenerative Design within a Marionettes World
}

Amazonas, Mariana, Master Student, m.amazonas@elemental.eco.br

Schumacher College/Plymouth University, Design Department, Address The old Postern, Dartington, Totnes, Devon, TQ96EA, UK

\begin{abstract}
This paper examines nature behaviour and patterns, finds parallels with social interactions and spots key aspects for developing genuine processes in collaborative and social innovation design. Through Literature review and practice-led research weave observations based on nature ancient wisdom. Nature vital energy is regenerative, it borns and expands naturally into an authentic and synergistic flow. Even entropy, when in equilibrium with this expansion movement, is a transformative agent, recycling the most diverse forms of life. Following a natural cycle of transformation, expansion and retraction. However, an unbalanced entropy energy might provoke an accelerated chaos expansion. On the one hand, nature brings this vital force in an evident and irrefutable way, because it has its integrity preserved, each element has an unshakable connection with its own essence. On the other hand, human social behaviour followed a completely different path. The Cartesian predominant mindset emphasizes standardized and controlled behaviours, seeking formulas of success and venerating specific models and ways of being. Although, it seems to be very efficient, it is highly destructive. It weakens our vital energy triggering an unbalanced entropy development, therefore the destruction of our own essence. As a result, we have been failing dramatically and losing what we care most. Such as freedom, happiness, engagement, ability of love, diversity, richness, creative potential, inner fire, resilience and, at last, our whole existence. Bearing in mind this framework, how can a design process derail this train and trigger genuine and living social processes, as nature does.
\end{abstract}

Keywords. Social Innovation; Regenerative design; Biomimetic; Wicked Problems; Complexity. 


\section{Introduction}

The observation of nature has been a source of inspiration for the most varied forms of knowledge. It is an ancestral practice, transversal to the most diverse cultures and areas of study. It is commonplace to find this approach in the field of traditional wisdom, to a certain extent it is how peasants know when it is time to sow the crop; or at other extreme, in strictly academic science, such as in the scientific experiments of physics, biology, and so many others. However, in addition to these more widespread practices, the natural world can also be a great ocean of inspiration to guide the understanding of design processes in social innovation, as we see, for example, in the work of the German author Johann Wolfgang Von Goethe.

With this inspiration, over 8 months of studies during an MA in Ecological Design Thinking, I developed a series of experiments better described in the chapter on Methods and Methodology, literature research and reflective practices that gave birth to some concerns, analogies and conclusions addressed in this article. Outlining the context in which we live and drawing parallels between the dynamics of social interactions and nature, it was possible to spot some key aspects for designers who boldly dare to seek alive and original processes.

In harmony with the theme developed through this article, these researches and observations are subjective processes and do not have the intention to be terminated in a definitive way. On the contrary, it makes sense that it should be updated and open to new understandings and insights. The complexity that we find in social processes invites us to expect non-linear and completely unpredictable conclusions. With this framework, in the next lines we will take a walk through the meanders of this wonderful and flawless source of knowledge, which for more than 4 billion years has been improving and regenerating.

\section{The Vital Energy of Creation as an Opposed Strength to Entropy and Chaos.}

Nothing is static, over time, everything is energy in expansion or retraction, in construction or destruction. The positive energy that drives life and nature growth shows us in each of its details, forms and creations an incessant search for harmony and balance. It is positive energy thriving and turning the inevitable entropy trend.

The constitution of our body, from the way we breathe to the distribution of our limbs, is the embodiment of this harmonic and natural geometry to everything around us. In balance, in contraction and expansion, in responsive movement, like a dance that reverberates in spiral from the center of the earth to the highest star we can imagine in the milky way and far beyond.

This universal pattern or in other words universal fingerprint, is extremely obvious when we rarely give ourselves time to stop, feel and observe. In the trunks of the trees that curl up, in the meandering of a river waters, small plants growing shape or on the stones turned by the waves of the sea.

It is extremely common and ordinary in the natural world to find the impulse of life flowing and growing freely in spirals, circular motions and in a myriad of many other forms. Leaves, fruits, flowers and seeds sprout in great abundance from the treetops. The latter, when they are ready, free themselves in profusion, scattered through the wind until they find a fertile soil. The energy of creation contained in a small seed is so great that by gathering in synch some basic elements, it expresses its full potential and can bring forth the greatest of all the trees. 
Image 1 - Example of a geometric spiral growth in nature

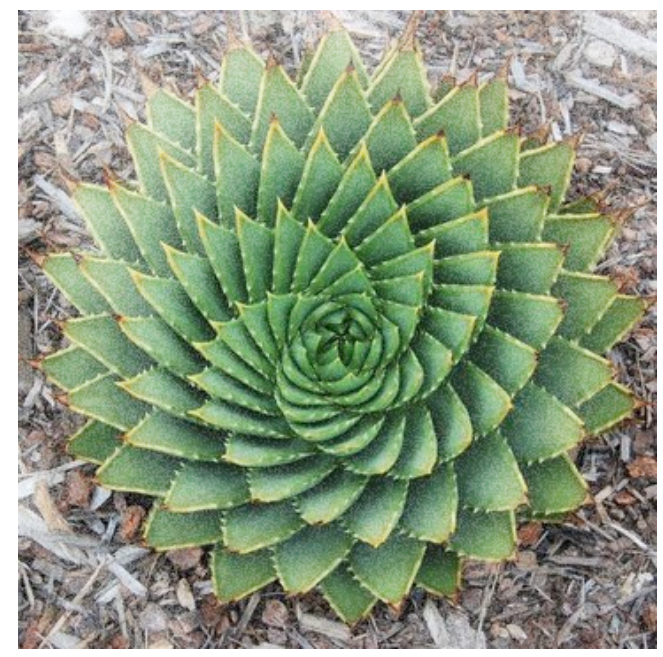

Source: personal library

The first figure of sacred geometry is the circle, whose circumference has neither beginning nor end and is therefore the geometer's image of entirety and eternity. As the simplest and most self-sufficient of space-enclosing shapes, and the matrix for all others, it is the natural symbol of that unique living creature, the cosmos (MICHELL, 2008, p.104)

Image 2 - Drawing of rocks in the see with charcoal chalk, Mattiscombe Beach, UK, 2019

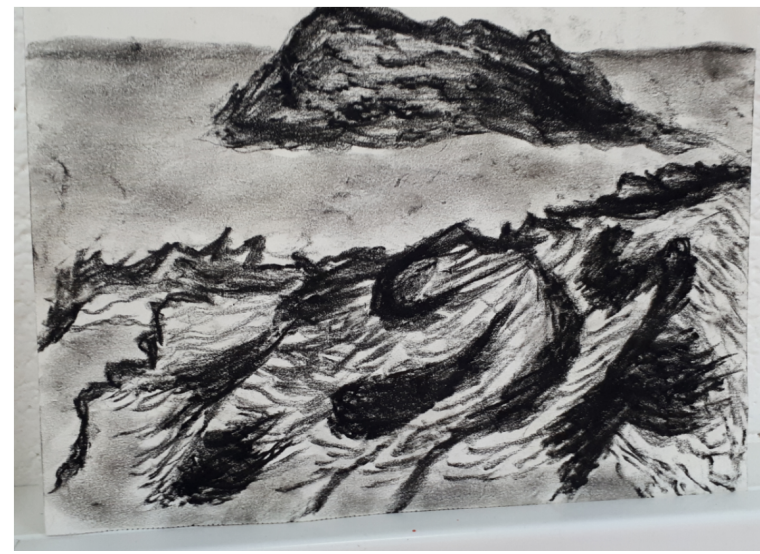

Source: personal library

Within a universe of so many and infinite possibilities, with such a powerfully vital energy in the natural impulse of life expansion, why do people or even entire societies prolong such a gloomy winter letting the energy of destruction to prevail? The answer to this question It is indeed a rather wicked problem, but our lifestyle over the last few centuries may give us some precious clues to what may be causing this imbalance. We become more and more isolated from nature, we have lost the ability to feel, reflect and walk in harmony with these natural laws. We created rules of conduct that overlaid everything, even if it means placing in the background the lives of other beings, including ours. This mechanism favors some who historically maintains power and is extremely efficient in preserving and prolonging disharmony. Far from our center, our essence, our creative potential and nature, we also move further and further away from this positive life energy, thus entropy and destruction have become stronger. 
I firmly believe that the multiple crises we are facing are symptoms of our pathological habit of understanding and experiencing ourselves as separate from nature, from each other and from community of life (WAHL, 2016, p.24).

This compartmentalized, limited, disconnected and simplified world view, which is indiscriminately widespread, is probably one of the main culprits of the destruction path we have been following. As we broadened our condition of knowledge and information throughout the history of the human being on earth, we also limited our world-reading ability with the Cartesian thought predominance and the mechanization of doing, intensified during the industrial revolution as predicted by Adam Smith himself.

The man whose whole life is spent in performing a few simple operations, of which the effects are perhaps always the same, or very nearly the same, has no occasion to exert his understanding or to exercise his invention in finding out expedients for removing difficulties which never occur. He naturally loses, therefore, the habit of such exertion, and generally becomes as stupid and ignorant as it is possible for a human creature to become. (SMITH, 1977, p.1040)

Unfortunately, Smith was right. We can see in our society the reflexes of this narrowed space for imagination. In a complex and connected world, we act and address problem solving as if they were isolated. We commit the atrocity of believing that the complexity of life could be solved with the same solutions we employ for any production line. We come to perceive the world in such an extremely limited way, that in many situations we seem blind, as brilliantly illustrated by Jose Saramago in his masterpiece Blindness.

The world we live is intrinsically related to the interpretation that each of us have reach based on a pool of different elements, such as our beliefs, faith, values, culture and knowledge. Apparently, a narrowed framework, which minimizes, separates, discriminates and pursues extreme simplification to promote productivity in assembly lines, has extrapolated the frontiers of the factories and has unfolded in a dominant way in the most diverse fields of our society. Thus, limiting our ability to think and consequently inhibiting and alienating our action in the world (ARENDT, 1958).

With this world bias, we applied this formula as a mirror of our own existence, reaching the point where we separate ourselves as a species, establishing the anthropocentric vision, where we are better and have more rights than any other living being.

However, the industrial revolution acted only as an intensifier factor of a long-standing problem in the fabric of human relations with itself and with everything that surrounds it. Certainly, this way of thinking and acting, in which we are a part without the consciousness that we are integrated into a much wider system, has become the dominant model and therefore this division has become even more evident. From our relationship with nature, through social classes, geographical borders, race, creed, political parties, other innumerable forms and even internally when we transformed the masculine and feminine into two distinct entities.

Even before the predominant scientific reductionist thought, we were greatly influenced by the Patriarchate who has become dominant in our thinking and acting, from the beginnings to the present times. This system has been extremely effective in its dissemination and own protection, but with the understanding that male energy is only one part of the dynamics between masculine and feminine, this reality has generated a dominant and unbalanced masculinity. As a plague that spreads without opponent, humanity is overwhelmed by aggressiveness, competition, control, rigidity, rationality and an over value of analytical thinking (WARING, 1990). 
We've being building walls to protect ourselves from what was out or diverse and ended up getting ourselves into a cage. We become absolute Gods of this incarcerated realm and reaped the geometry of imbalance.

\section{Finding a Path to a Regenerative Authentic, Free and Vital Social Design Flow.}

If every being is unique and at the same time the manifestation of an entity that covers all life on earth: the great Gaia system (HARDING, 2013); individuation is a narrow perspective of reality. However, it is in this small container of life that an individual finds his/her vital energy, his/her pulse and what gives meaning to what could be just a heap of cells and bacteria. Every and each being from this planet is at the same time, part of the system and the whole system.

This is an intriguing dialectic, looking to the elements of nature as an inspiration, water, which is apparently an extremely flexible and moldable element/individual, demonstrates a unique and almost unbeatable personality. In the Archetypal Movements of Water chapter, Schwenk describes that gravity is in opposition to water's natural movement, in other words water in relationship with earth behave differently than if it was without either interference or resistance. In a combined vision, they - earth and water - are creating something or flowing together, a river for instance. Nevertheless, in an individual perspective, they are fighting to shape each other. In Schwenk's book, Sensitive Cahos, of flowing forms in water and air he illustrates that water will always seeks to return to an original spherical form.

We see moving water always seeking a lower level, following the pull of gravity. In the first instance it is earthly laws which cause it to flow, draw it away from its spherical form and make it follow a more or less linear and determined course. Yet water continually strives to return to its spherical form (SCHWENK,1965, p.13).

Image 3 - Water natural spherical form

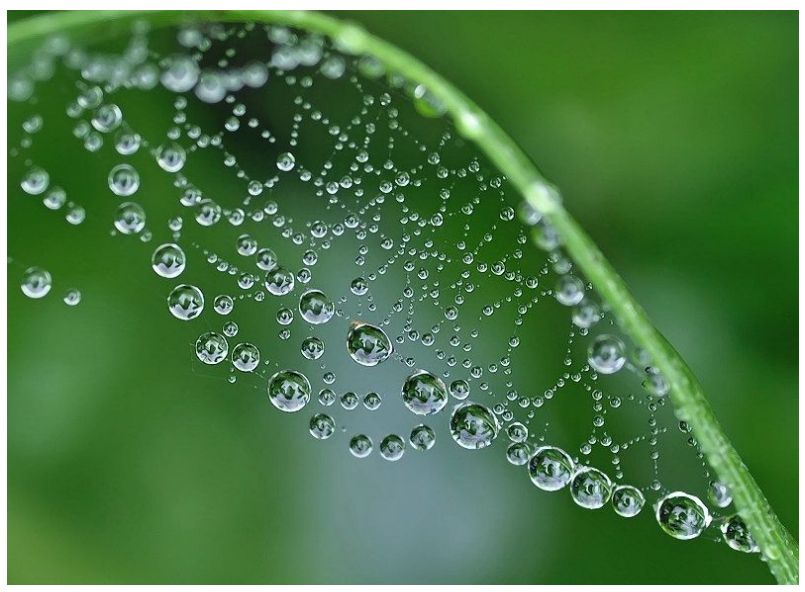

Source: pictures 4 ever

A designer who really wants to inspire or facilitate a genuine social innovation process should pay special attention to this reflection, the fluid dance between what is the creative and individual nature of one and the oceanic dilution in the processes of collaboration and collective creation. This process becomes even more sensitive if we consider the framework that I initially described of our extreme standardized society in which we live. 
As Schwenk demonstrates, there is a constant and incessant struggle between water and land, once they are two entities with their own personalities. However, since it is the nature of water to seek its original spherical shape, after all, it will always thrive. Even if it must cross the Atlantic Ocean. (p.19) And this led me to more questions, how to trigger an authentic form from individuals through a collective process of creative expression?

Mindful of those challenges, a designer must keep a continuous deep questioning practice. How can we create a gentle structure that guide and at the same time allows the unexpected to emerge? Find the means to let emergence of what is genuine from each one and from a collective of people is also to trigger a positive vital energy, to radical innovation and therefore to a regenerative design.

However, many other challenges can arise during a collective construction process, observing groups work dynamics, the tyranny of constantly attempting to impose what was born from individuals' point of view became very evident. To a certain extent, it is easy to justify this behavior by the desire for power or even as an innate survival self-defense automatized reaction. People, very often are jailed in the perspective of (respectfully) fighting, not really building ideas together, but trying to impose their own thoughts, as the narrowest view of the battle between water and earth. This can be extremely limiting in a creative process. By widening the perspective, it also creates automatic, pre-fabricated and unoriginal ideas, reinforcing marionettes behaviors.

This is a terrifying view, mainly when there is a rising massive society disengagement or even rejection with diversity and non-conventional ways of living. This kind of oppression directly referred me to a concept developed by Étiene de La Boétie, a French philosopher who in the 16th century wrote a book about Voluntary Servitude.

Étiene argues that we are all tyrants and tyrannized, in this game people give up their greatest treasure, freedom itself. Authoritarianism and polarized discourses are internalized, and eventually people give up their freedom, allowing their selves to be tyrannized, and whenever they can, replicate the same behavior with others. What would a person gain from this? Precisely the lack of responsibility for the result of anything. This is a safe, child-friendly place where people do not have to think or take risks.

In a wider framework, this is a very familiar place along human journey on earth until nowadays. For instance, currently the consumer society gave up of their thinking ability, replacing it to a massive replicated dictatorial march. Whoever controls this society, controls it not only because seduce people but mainly because they want to be controlled. Narrowing down to a design process, it is quite easy almost a commonplace to observe the artifacts that each participant brings to assert a specific idea or agenda. The giant ability to build plots and traps is subtle and at the same time extravagant. In my interpretation, the designer, who is inadvertently unaware of these parallel processes can easily be swept away by a flood without realizing what hit him/her.

However, radical collaboration and freedom is a basic principle of genuine design creation, anything different from this is a place or a habit that It should be deeply transformed. On its own, this is already a matter of extreme relevance, but it still gains new tones when it comes to how to respond and work with the tyranny of those involved in the creative process. On the top of it, "The wicked problem solver has no right to be wrong-they are fully responsible for their actions (RITTEL, 1972, p.16). Thus, the designer total responsibility is a key element. 
In a world of infinite possibilities, diving in the center of the process of creation, which its most sublime representation is life itself and consequently natural evolution. There are two antagonistic interpretations, the first one is the renowned Charles Darwin's Theory of Species of Evolution, the second and most recent is a re-interpretation of it by Lynn Margulis. The former, spots competition as a powerful development tool. The latter demonstrates the importance of symbiosis and contradictorily spots cooperation as a tool of development (Symbiogenesis). On that note, radical collaboration is very likely to be another key element to craft genuine an innovative design process.

\section{The Designer Toolbox as a Guardian of a Genuine Collaborative Process}

On the one hand, design tools are a key guide to promote an authentic flow during the creative development. The complexity of human thoughts or feelings and their respective triggers for some very weird reactions cannot be dealt with in depth during a design process. A facilitator must stay respectfully without losing a flow form. On the other hand, an authentic creative process must find space to emerge spontaneously, otherwise there is a great risky of facilitate just the same repetitive solutions.

During group works, one can face the most profound human fears, the feeling of not being heard, belonging, disapproved, in competition, anger, in ability of expressing their selves and mainly oppression. As well as diametrically opposed experiences, the immense joy of seeing a product of collective creation born, friendship, love, care, spirituality and a high state of the soul. Because of this intricate chain of feelings, the delicate structure that the design-thinking tools create became even more important, serving as a particularly feature of support network on the more tortuous parts of the road. Acting as a buoy saves lives during the times when our fears seem to drown us.

In this pendulum movement, the risk once again is to find a new tyrant to deliver our freedom. The design's structure and tools are master springs, structuring guides and providing a highly fertile and creative environment. But to place all responsibility on the tools, it might be one of the many forms that tyranny can assume. Like everything else in life, there is an alchemical measure for getting completely different emergent properties. There are times where the most inspired solutions will come from wobbly footsteps over never-before-traveled terrain and not from preconceived tools. The delicacy is in staying at the same time firm and flexible to realize when the background music needs to be different.

As well as the tools, an exercise of collective creation contains the same ambiguity. When the form of construction demands silencing the individual expression to the benefit of collective creation. At this point, I want to emphasize that I am not talking about radical collaboration, I mean radical commitment with the sake of the process. This can be a delicate and dangerous dance, which can both spring the maximum creative potential of a group or lead to a state of disengagement. The mastery of the Designer is to lead in a sensitive and inspiring way this alchemical process, however this sensitivity can only arise from a field of transversal knowledge and the widest spectrum and different forms of intelligences, senses or in other words, an integrated perception ability. Where the mind, the intuition and the heart dance and work in fine harmony and connected tune. 


\section{Methods and Methodology}

The reflections woven in this paper were developed through several different practices and experiments during an Ecological Design Thinking Master. Throughout all the modules of the course, theory was blended and interconnected with individual and mainly collective experiments. This learning method provides deep insights, knowledge embodyment and on top of that originality in creative processes. It is worth noting, some practices such as those described below.

Nature deep experience: long hours of nature observation, developing free creative or extremely detailed designs of plants, forests and rivers, inspired by Goethean Science observations techniques. As well as, meditative and nature learning practices, inspired by Joanna Macy's deep nature observations techniques (MACY, 2014), such as deep silence walk through the woods and by the coast;

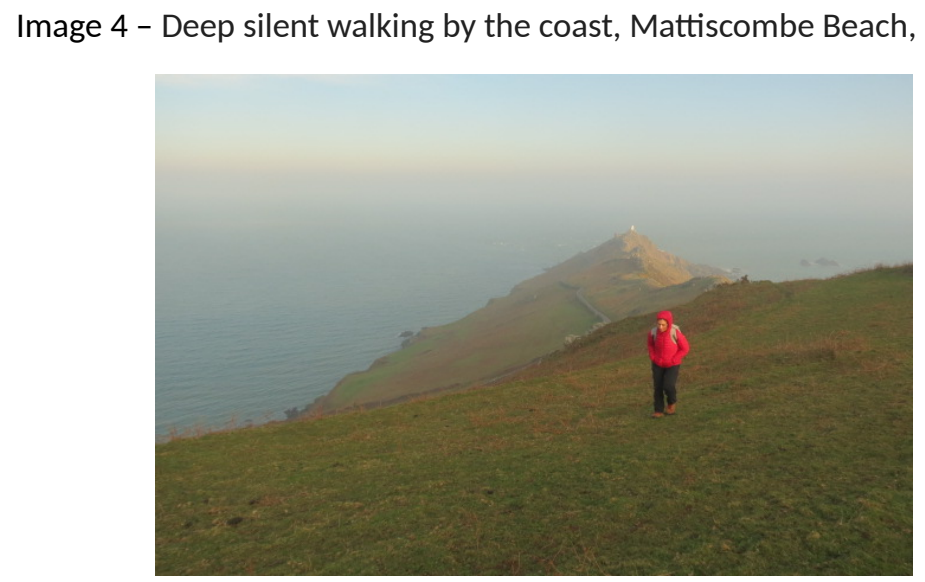

Source: personal library

Hand made artfacts: Clay and timber group workshops, with the intention of promoting a meditative and unique mindful state that manual works provoke. Moreover, it was adopted a system thinking mindset, with a cradle to cradle approach, where the work was initiated from the clay and wood harvest stage, through the various forms of treatment required to prepare the raw material, until the manual final creation. It was build a fertile field to individual and collective reflexive moments, taking advantage of this raised level of understanding and grounding, with this quality of focus and integrated feeling, as well as a more subtle senses.

Image 5 - Timber workshop: horse shavers, UK, 2019

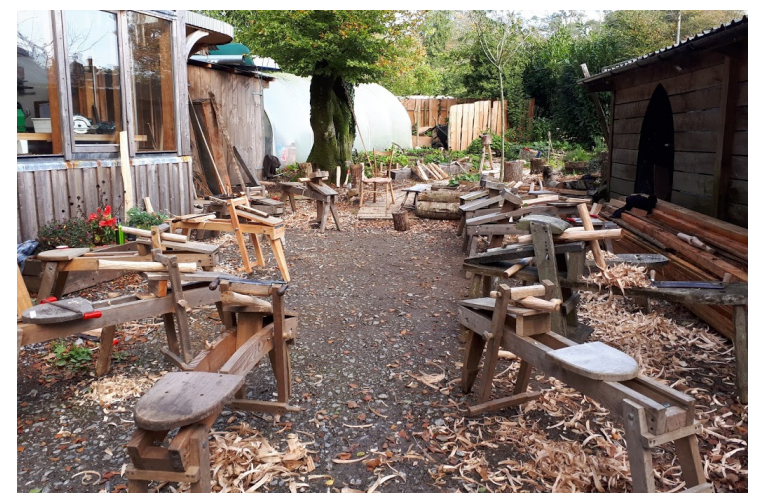

Source: personal library 
A design process: At last, a profound transformative work journey, through the development of a real project, problem and place. The Ecological Design Thinking Master students were commissioned by a Trust, called Choice, which worked for the last 20 years in UK prisons improving the visitation process. Their main objective with this project was to tackle children's traumatic experiences, due to safety procedures, and to improve relationship between the inmates and their relatives. The complex practice of dealing with several stakeholders, a number of very restrictive and rigid rules, different backgrounds, collective creative activities and the tough process of understanding a wicked problem became a key inspirational element of this article. Beyond the designed product delivered itself, this experience unfolded and enriched my reflection around group pattern behaviors.

Image 6 - The prison gates, UK, 2019

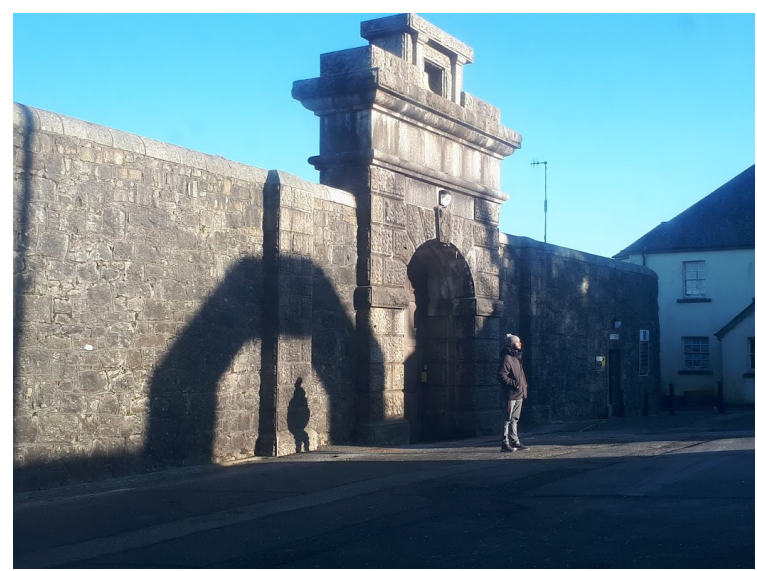

Source: personal library

Image 7- A prison Inmate draw, UK, 2019

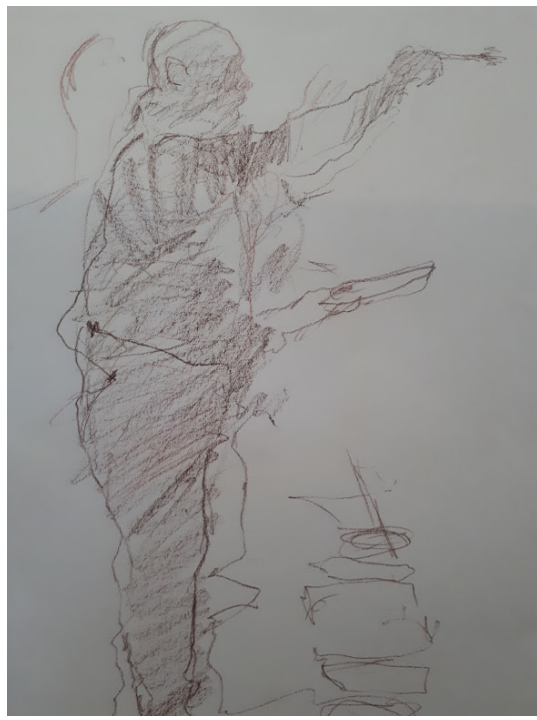

Source: personal library

\section{Conclusion}

In conclusion, I wander what happens to water, when by one circumstance, it is forced to remain static, prevented from following its natural pulse and remaining a lake trapped forever. 
Somehow, it continually managed to avoid all twists and turns from evaporation or expansion caused by heavy rains. In this case, what nature teaches us is that when water loses a battle and is prevented from following its natural path for a certain amount of time, stagnation becomes death and rot. Voluntary servitude finds many similarities with stagnation and the consequences of this is a sick society. People have all the possibilities but give up of their own freedom for self-indulgence. Finally, spotting a design creation process we can expect a similar outcome, mediocrity, disengagement and frustration.

The perfect balance between, an individual and its multiple interactions / creations in a collective or even how much structured by preconceived tools a process needs to hold is a true design wicked problem. It is still 'indetermined' (BUCHAMAN, 1992, p.16). Hence, what resonates for me now are some early indications of some very basic fundamental principles that a designer needs to be mindful of:

- Firstly, be aware and attentive to the gigantic relevance of all kinds of visible and invisible elements and people personalities that surround you. Be responsive to it, as nature does;

- Keep the fire of intention and full responsibility burning and at the same time do not let anything save you from your freedom and open thinking;

- Be water that pulsates and thrives in finding its original form, whilst dancing with everything that surrounds you and which is also part of who you are;

- Mindfully keep a continuous self-observation practice and dedicate all the necessary efforts to preserve your integrity and a living true essence.

- Take radical collaboration as a mantra, seek the harmony and structure necessary for each situation, each experience will demand a unique balance to trigger an authentic flow. Keep questioning over and over;

- Finally, be yourself the greatest and unique creation of your own life, alone and together.

\section{$7 \quad$ References}

ARENDT, Hannah, The Human Condition, Published by University of Chicago Press, 1958.

BUCHAMAN, Richard, Wicked Problems in Design Thinking, Source: Design Issues, Vol. 8, No. 2, (Spring, 1992), pp. 5-21 Published by: The MIT Press, URL:http://www.jstor.org/stable/1511637 Accessed: 13/11/2018 15:00.

HARDING, S., Animate Earth: Science, Intuition, and Gaia. Green Books, $2^{\text {nd }}$ Edition, 2013.

LA BOÉTIE, Étienne, The Politics of Obedience: The Discourse of Voluntary Servitude, 1576, original title Discours de la servitude volontaire ou le Contr'un, France.

Available from: http://oll.libertyfund.org/titles/boetie-the-discourse-of-voluntary-servitude Accessed: 14/11/2018 10:00

MACY, Joanna and BROWN, Molly Young, Coming Back to Life_ The Updated Guide to the Work that Reconnects, 2014, New Society Publishers. 
MARGULIS, Lynn, recipient of the National Medal of Science, is interviewed by Jay Tischfield, chair of Genetics department at Rutgers, The State University of New Jersey. Available from: https://youtu.be/KIhW12dGfFk. Accessed 13/11/2018 15:01.

MICHELL, John, The Dimensions of Paradise: Sacred Geometry, Ancient Science, and the Heavenly Order on Earth, Inner Traditions, 2008, Originally published in 1971 by Garnstone press.

SARAMAGO, Jose. Blindness, Published by Harcourt Books, Orlando, Florida, U.S.A. (1998)

SCHWENK, Theodor, Sensitive Cahos, In Archetypal Movement of Water. Rudolf Steiner Press (Ed), 1965. Second impression, 1971, London, Verlag Freies Geistesleben.

SMITH, Adam, The Wealth of Nations - An Inquiry Into the Nature and Causes of the Wealth of Nations, University of Chicago Press, 1977

WAHL, Daniel Christian, Designing Regenerative Cultures, Published by Triarchy Press, 2016

WARING, Marilyn, If Women Counted: A New Feminist Economics, Harper Collins, Publishers, San Francisco, Paperback Edition, 1990. 